Asión Suñer, Ana.

Personal Investigador en Formación Gobierno Aragón. Departamento de Historia del Arte, Universidad de Zaragoza.

\title{
Sinergias y despedidas: el arte audiovisual como reflejo de la emigración española actual a Europa.
}

\section{Synergies and farewells: audiovisual art as a reflection of the current Spanish emigration to Europe.}

TIPO DE TRABAJO:

Comunicación.

PALABRAS CLAVE:

Arte audiovisual, emigración española, globalización, ficción.

KEY WORDS:

Audiovisual art, Spanish emigration, globalization, fiction.

\section{RESUMEN.}

Como consecuencia de una globalización cada vez más acusada, el fenómeno migratorio ha cobrado en los últimos años un especial interés en los diferentes medios. Las aportaciones derivadas de las artes visuales en relación con este tema han sido variadas, con exposiciones como "Artistas Acoge Arte + Inmigración" (Antequera, Málaga; del 12 al 26 de febrero de 2016), "\#SIN FILTROS. Miradas al éxodo que Europa no quiere ver" (Matadero Madrid; del 26 de mayo de 2016 al 8 de enero de 2017) o "Somos migrantes" (León; del 16 al 31 de enero de 2017).

Sin embargo, el caso concreto de la emigración española a Europa ha adquirido un mayor protagonismo en plataformas audiovisuales (cine y televisión, principalmente, pero también en el videoarte: "Lo inconmensurable", CentroCentro Madrid, del 29 de abril al 28 de agosto de 2016), las cuales se han hecho eco de una situación cada vez más normalizada y cotidiana. En este caso, el audiovisual se constituye como un medio perfecto en sus diferentes plataformas para la transmisión de estereotipos mantenidos de forma diacrónica, sobre los que hay que bucear para hallar el profundo poso crítico que transmiten hacia las actuales situaciones en Europa.

En el ámbito español, la ficción audiovisual (Hermosa juventud, 2014; Perdiendo el Norte, 2015) ha sido y es uno de los principales canales donde se ha visto reflejado esta realidad. Ésta es precisamente la que muchas veces permite poner cara a estas situaciones, actuar como un lienzo donde se plasma una reactualización de las escenas costumbristas que antaño poblaban los cuadros. Ahora la situación es distinta. Las circunstancias han hecho que el escenario cambie, pero no sus protagonistas. 


\section{ABSTRACT.}

As a result of an increasingly marked globalization, the migration phenomenon has gained in recent years a special interest in the different media. The contributions derived from the visual arts in relation to this theme have been varied, with exhibitions such as "Artists Acoge Arte + Inmigración" (Antequera, Málaga, from February 12 to 26, 2016), "\#SIN FILTROS. Look at the exodus that Europe does not want to see "(Matadero Madrid, from May 26, 2016 to January 8, 2017) or" We are migrants "(León, January 16-31, 2017).

However, the specific case of Spanish emigration to Europe has acquired a greater role in audiovisual platforms (mainly cinema and television, but also in the video art: "The incommensurable", CentroCentro Madrid, from 29 April to 28 August 2016), which have echoed an increasingly normalized and everyday situation. In this case, the audiovisual is a perfect medium in its different platforms for the transmission of stereotypes maintained in a diachronic way, on which to dive to find the deep critical ground that they transmit to the current situations in Europe.

In Spanish, audiovisual fiction (Hermosa juventud, 2014; Perdiendo en Norte, 2015) has been and is one of the main channels where this reality has been reflected. This is precisely what often allows facing these situations, act as a canvas where a reactualization of the customs scenes that once populated the paintings. Now the situation is different. Circumstances have made the stage change, but not its protagonists.

\section{CONTENIDO.}

Nacen a todas horas, en cualquier lugar, muros que devuelven la alzada al cielo (muros nubes muros redes), paralela, cenital, la vida se revela horizonte, cada nube es un hombre, cada hombre es un puente.

Alejandro Díaz del Pino ${ }^{1}$

"La historia de la humanidad es la historia del nomadismo" (La historia de la humanidad..., 2013). Así de rotunda se mostraba la escritora Laura Restrepo ${ }^{2}$ en junio de 2013, quien destacaba en las mismas declaraciones como este rasgo es algo inherente al ser humano, un fenómeno fundacional. Está claro que las olas migratorias han marcado el devenir de la historia, y con ello todos los aspectos que, como sociedad, han rodeado a cada habitante del planeta, desde la economía hasta la cultura.

Restrepo hace hincapié en el tratamiento que la literatura ha dado a este tipo de movimientos, desde la Biblia hasta las narraciones actuales. Una disciplina que no se ha mantenido al margen de estos sucesos, pero que tampoco ha sido la única. Desde el arte; pintura (Los emigrantes, 1852-1855, Honoré Daumier; Serie de la migración, 1940-1941, Jacob Lawrence), escultura (La madre del emigrante, 1970, Ramón Muriedas; Viajeros, 2013, Bruno Catalano), fotografía (Buscando una señal, 2013, John Stanmeyer; ¿Costumbre o indiferencia?, 2014, José Palazón) o cine (Españolas en París, 1971, Roberto Bodegas; Lamerica, 1994, Gianni Amelio), han participado de esta temática, aportando diferentes puntos de vista a una realidad cuya crudeza resulta atemporal.

Resultaría tedioso, e innecesario dada la acotación de espacio, realizar en estos instantes un recorrido por todas olas migratorias más destacadas de la historia de la humanidad. Es por ello por lo que, en esta ocasión, se ha decidido elegir como objeto de estudio la emigración española actual a Europa, un fenómeno que muchas veces pasa desapercibido en la sociedad de hoy en día.

El aumento de la globalización en las últimas décadas ha tenido como consecuencia, entre otros, que actualmente los medios de comunicación actúen como altavoz de cualquier suceso que tenga lugar a nivel mundial. El potencial usuario de los mismos consume información a distintos niveles, dependiendo éstos de la proximidad que dichos acontecimientos tengan con el individuo en cuestión y su entorno. El sujeto puede por tanto desarrollar empatía por situaciones que le resulten geográficamente lejanas, y que incluso este vínculo repercuta en sus propias actuaciones. Uno de los ejemplos más reseñables en la actualidad son las grandes olas migratorias derivadas de las catástrofes bélicas que atraviesan algunos países como Siria o Irak. En forma de naufragio, salto masivo a vallas

${ }^{1}$ Cita con la que abre el catálogo de la exposición "Artistas Acoge Arte + Inmigración” (Antequera, Málaga; del 12 al 26 de febrero de 2016).

${ }^{2}$ Escritora y periodista colombiana (Bogotá, 1950), entre sus obras destacan Dulce compañía (1995), La novia oscura (1999) o Delirio (2004). 
fronterizas o llegada a campamentos temporales, cada día el mundo entero se levanta con la crónica de una nueva huida. Sucesos que no dejan indiferente a nadie, pero que al mismo tiempo generan reacciones distintas. Los artistas, en sus múltiples formas de crear y expresarse, tampoco se han mostrado impasibles ante estos sucesos. Algunos de ellos han visto en la pintura, la escultura o la fotografía, medios donde, sobre todo, denunciar estas situaciones. De hecho, las aportaciones derivadas de las artes visuales en relación con este tema han sido variadas.

Una de las muestras más multidisciplinares llevadas a cabo en relación con esta temática fue "Artistas Acoge Arte + Inmigración" (Antequera, Málaga; del 12 al 26 de febrero de 2016). Durante la misma, medio centenar de artistas ${ }^{3}$ aportaron obras de distinta naturaleza, desde ilustración, diseño gráfico o fotografía hasta arte plástico. Planteado desde la asociación Málaga Acoge, el proyecto sin embargo no se concibió con un objetivo meramente lúdico: su labor fue también la de concienciar sobre los derechos y la igualdad de oportunidades de las personas inmigrantes. El arte como medio que traspasa fronteras y actúa como objeto de lucha, un aspecto que fue reconocido por la web European Website on Integration de la Comisión Europea. ${ }^{4}$ Las obras, que en un principio simplemente iban a formar parte de una exposición virtual, podían ser adquiridas por cualquier usuario, destinándose la recaudación obtenida a diferentes actividades llevadas a cabo por la entidad. Para favorecer este aspecto, se puso a disposición de todos los interesados un catálogo con información sobre los diferentes trabajos. ${ }^{5}$ Entre los mismos se podían encontrar obras de distinto origen, que compartían mensaje pero diferían en el vehículo utilizado para su transmisión. Un ejemplo de esta dicotomía aparece en "Héroes de patera". El drama del viaje visto a través de la imaginación de un niño subsahariano (Jorge Berrocal, lápiz, tinta y color digital), donde la gradación grisácea del dibujo únicamente se ve alterada por la tonalidad marrón del joven protagonista; una atmósfera que se contrapone con el trabajo que aparece a su lado en el catálogo, Sin título (Betty Bundy, técnica mixta sobre papel de alto gramaje), en el que la palabra "Hope" presenta unas tonalidades triunfantes y patrióticas, en un abanico de azules, magentas y blancos que sin duda remiten a la nación capitalista por excelencia: Estados Unidos. Dos polos opuestos que coexisten dentro del mismo planeta, dos realidades completamente antagónicas separadas en este caso por unos pocos centímetros.

Siguiendo esta misma línea, tanto "\#SIN FILTROS. Miradas al éxodo que Europa no quiere ver" (Matadero Madrid; del 26 de mayo de 2016 al 8 de enero de 2017) como "Somos migrantes" (León; del 16 al 31 de enero de 2017) buscan en la inmediatez de la fotografía el medio de acercar al público esta realidad. La primera de ellas, patrocinada por Metro Madrid y ubicada en la Casa del Lector, recogió a través de cincuenta instantáneas el horror que experimentan las personas que se ven forzadas a huir de sus hogares por culpa de la guerra. Imágenes que traspasan la cámara, se introducen en la mente del espectador y le hacen reflexionar acerca de una situación aberrante e inhumana que, como el título de la propia muestra indica, no se puede esconder ni disimular a través de ningún filtro.

Proyectos que traspasan fronteras, que se mueven entre el placer estético que ofrecen las diferentes manifestaciones artísticas en las que se basan y la necesidad de contar, aunque también de criticar y denunciar, la situación que atraviesan los inmigrantes de todo el mundo.

El caso concreto de la emigración española a Europa, quizás menos visible a nivel mediático aunque no por ello menos importante, ha adquirido un mayor protagonismo en plataformas audiovisuales (cine y televisión principalmente, pero también en el videoarte), las cuales se han hecho eco de una situación cada vez más normalizada y cotidiana. En esta ocasión, estas manifestaciones se constituyen como un medio perfecto en la transmisión de estereotipos mantenidos de forma diacrónica, sobre los que hay que bucear para hallar el profundo poso crítico que transmiten hacia las actuales situaciones en Europa.

Comisariada por Aimar Arriola y Soledad Gutierrez, "Lo inconmensurable" (CentroCentro Madrid, del 29 de abril al 28 de agosto de 2016) reflexiona sobre Europa a partir de la colección Pi Fernandino, ${ }^{7}$ preguntándose hasta dónde llegan los límites (en todos los sentidos) del viejo continente. Disparidad de puntos de vista, heterogeneidad de visiones acerca de temas que han formado y forman parte de un territorio disperso (la emigración, la propia historia de los estados, los derechos humanos, los conflictos bélicos,...).

\footnotetext{
${ }^{3}$ Algunos de los profesionales que participaron en la exposición fueron Antonio Berrocal, Cristina Sánchez, Eryk Pall, Narita Estudio, Paula Vincenti, Pedrita Parker, José Medina Galeote o Hintercalada.

${ }^{4}$ Concretamente fue considerada "Buena práctica para la integración".

${ }^{5}$ Catálogo de la exposición "Artistas Acoge Arte + Inmigración", 2015.

[https://issuu.com/malagaacoge/docs/artistas_acoge_expo_catalogo_sept20] [Última consulta: 9 de marzo de 2016].

${ }^{6}$ Promovida por Entreculturas (ONG vinculada a la Compañía de Jesús), el Servicio Jesuita a Migrantes-España (SJM-España) y la Comisión Episcopal de Migraciones (CEM), su origen parte de la exposición Todos Somos Migrantes, celebrada en México por parte del Servicio Jesuita a Migrantes México.

${ }^{7}$ Propiedad de Helena Fernandino y Emilio Pi (Pamplona, 1954), la mayor parte de las piezas están dentro del formato del videoarte (300 obras). Algunas de ellas han sido exhibidas en el Museo Nacional Centro de Arte Reina Sofía, Centro de Arte Dos de Mayo o Centro Pompidou, entre otros.
} 
Dieciséis artistas internacionales ${ }^{8}$ ponen voz a través de sus obras a todos estos aspectos, expresándose como cada uno de ellos mejor sabe: mediante el videoarte. No se busca en ningún caso generar un relato, una narración, sino simplemente que la muestra actúe como contenedor de distintas propuestas que hablan, opinan y analizan Europa. La exposición acogió además dos performances, una de Dora García y otra de Mónica Ross.

Desde una manifestación completamente diferente a las anteriormente mencionadas, lo cierto es que en el ámbito español la ficción audiovisual ha sido y es uno de los principales canales donde se ha visto reflejada la realidad de los emigrantes españoles a Europa. Ésta es precisamente la que muchas veces permite poner cara a estas situaciones, actuar como un lienzo donde se plasma una reactualización de las escenas costumbristas que antaño poblaban los cuadros. Ahora la situación es distinta. Las circunstancias han hecho que el escenario cambie, pero no sus protagonistas. Los géneros desde donde se han plasmado todas estas situaciones son dispares, aunque destacan principalmente el drama y la comedia. Dentro del cine español resulta inevitable hacer referencia a dos de las películas más relevantes dentro de esta temática, ambas estrenadas en 1971: Españolas en París (Roberto Bodegas) ${ }^{9}$ y Vente a Alemania, Pepe (Pedro Lazaga). ${ }^{10}$ Sin embargo no son las únicas que retrataron el éxodo que vivieron muchos españoles durante los años sesenta y setenta, ya que más recientemente se pueden encontrar ejemplos como El techo del mundo (1995, Felipe Vega), ${ }^{11}$ Un franco, 14 pesetas (2006, Carlos Iglesias) ${ }^{12}$ o Las chicas de la sexta planta (Les femmes du 6e étage, 2010, Philippe Le Guay). ${ }^{13}$

Dentro del género dramático, se alza como uno de los ejemplos más relevantes la película Hermosa juventud (2014), ${ }^{14}$ en la que se cuenta la historia de Natalia y Carlos, una pareja que decide emigrar al extranjero en busca de un futuro mejor. Una estética asfixiante, donde se mezcla la necesidad y la desesperación, y cuya única salida es, una vez más, huir. Retratos que, como ocurría con las fotografías anteriormente analizadas, obligan al espectador a repensar sobre una situación que, esta vez, le resulta más cercana. Se encuentra en ese "primer nivel" de noticias, ya que se trata de un suceso que le podría estar pasando a cualquier persona de su entorno, incluso a sí mismo. Todas estas sensaciones se acompañan de una interpretación veraz y contenida, que el propio Carlos Boyero califica de la siguiente manera (Boyero, 2014): "Los actores jóvenes rebosan naturalidad, los diálogos y las situaciones son creíbles, nada resulta gratuito o suena a impostura". Son varios los críticos que, a su vez, han resaltado el protagonismo que el director da a las redes sociales, unas plataformas que, dada su actualidad y repercusión en estos momentos, le sirven para lograr que el espectador empatice todavía más con la historia y sus personajes.

Desde una atmósfera completamente distinta, Perdiendo el norte $(2015)^{15}$ recoge el testigo de Vente a Alemania, Pepe $e^{16}$ para contar esta terrible realidad desde un punto de vista humorístico. En esta ocasión la historia está protagonizada por Hugo y Braulio, dos universitarios que, dada la situación de desempleo que sufren en España, deciden emigrar a Alemania. En el país germano descubren que la situación no es tan buena como ellos se imaginaban. Los tópicos están presentes a lo largo de toda la película, algo que quizás a primera vista desvirtúa la importancia del problema que están retratando. Sin embargo, sería un error caer en este análisis tan superficial, puesto que lo que convierte este largometraje en algo más que otra comedia de enredo, es la delicadeza con la que Velilla sabe tratar esta situación. Dentro de esta línea habla Oti Rodríguez Marchante en ABC (Rodríguez Marchante, 2015): “(...) los personajes saben cómo tratar la seriedad de esa "lacra» de la juventud española mejor preparada de la historia que huye a perfeccionar su máster en lavar platos en un Berlín entre majo y mágico: Berlín el encantador".

\footnotetext{
${ }^{8}$ Victor Alimpiev, Ibon Aranberri, Angela Bulloch, Tacita Dean, Gintaras Didžiapetris, Willie Doherty, Jon Mikel Euba, Harun Farocki, Dora García, Doug Hall, Chris Marker, Antoni Muntadas, Hans Op de Beeck, Martha Rosler, Monica Ross y Samuel Stevens.

${ }^{9}$ España, 1971. Director: Roberto Bodegas. Guion: José Luis Dibildos, Roberto Bodegas, Antonio Mingote y Christian de Chalonge. Fotografía: Rafael de Casenave. Música: Carmelo Bernaola. Intérpretes: Ana Belén, Laura Valenzuela, Tina Sáinz, Máximo Valverde.

${ }^{10}$ España, 1971. Director: Pedro Lazaga. Guion: Vicente Escrivá y Vicente Coello. Fotografía: Raúl Pérez Cubero. Música: Antón García Abril. Intérpretes: Alfredo Landa, Tina Sainz, José Sacristán, Manuel Summers.

${ }^{11}$ España-Francia-Suiza, 1995. Director: Felipe Vega. Guion: Felipe Vega y Julio Llamazares. Fotografía: Denis Jutzeler. Música: Bernardo Bonezzi. Intérpretes: Santiago Ramos, Emmanuel Laborit, Nathalie Cardone, Mulie Jarju.

${ }^{12}$ España, 2006. Director: Carlos Iglesias. Guion: Carlos Iglesias en colaboración con Central de Guiones. Fotografía: Tote Trenas. Música: Mario de Benito. Intérpretes: Carlos Iglesias, Javier Gutiérrez, Nieves de Medina, Isabel Blanco.

${ }^{13}$ Francia, 2010. Director: Philippe Le Guay. Guion: Philippe Le Guay y Jérôme Tonnerre. Fotografía: Jean-Claude Larrieu. Música: Jorge Arriagada. Intérpretes: Fabrice Luchini, Sandrine Kiberlain, Natalia Verbeke, Carmen Maura.

${ }^{14}$ España, 2014. Director: Jaime Rosales. Guion: Jaime Rosales y Enric Rufas. Fotografía: Pau Esteve Birba. Música: Juan GómezAcebo. Intérpretes: Ingrid García Jonsson, Carlos Rodríguez, Juanma Calderón, Inma Nieto.

${ }^{15}$ España, 2015. Director: Nacho G. Velilla. Guión: Antonio Sánchez, David S. Olivas, Oriol Capel y Nacho G. Velilla. Fotografía: Isaac Vila. Música: Juanjo Javierre. Intérpretes: Yon González, Julián López, Blanca Suárez, Miki Esparbé.

${ }^{16}$ En ambas películas aparece el actor José Sacristán, aunque el papel que desempeña en el largometraje de Velilla es ya el del emigrante veterano que conoce el desencanto del viaje a Alemania en busca de un futuro mejor.
} 
Adoptando una estructura cercana al spin off respecto a Perdiendo el norte, Antena 3 llevó a cabo en televisión Buscando el norte, ${ }^{17}$ una serie de ocho capítulos en los que de nuevo, la emigración a Alemania por parte de jóvenes españoles se convierte en la premisa principal de la trama. En este caso no obstante sus índices de audiencias fueron bajos, por lo que la serie no fue renovada.

La pintura, la fotografía, el videoarte, el cine o, en definitiva, las artes visuales en general, no se han mostrado nunca al margen de lo que sucedía en la sociedad. Han sido juez y testigo de las transformaciones del ser humano, sus inquietudes, anhelos y temores. Como se ha podido comprobar, el fenómeno migratorio ha estado presente en las mismas durante prácticamente toda la historia, cobrando especial fuerza a partir de los acontecimientos de los últimos años. En este caso, las nuevas plataformas artísticas han sido las que de especial manera han recogido el drama vivido por millones de personas que han tenido que dejar su hogar en busca de un futuro mejor. Concretamente en el caso de los emigrantes españoles a Europa se ha visto como el medio audiovisual ha sabido canalizar parte del sentimiento experimentado por éstos, retratando, esta vez sobre celuloide, la realidad que muchas veces los medios de comunicación no desean mostrar y que, por lo menos todavía, tampoco protagoniza ningún estudio serio sobre papel.

\section{FUENTES REFERENCIALES.}

ALBA, S. 2004. Miradas de emigrantes. Imágenes de la vida y cultura de la emigración española en Europa en el siglo XX. Madrid: Fundación 1일 de mayo. ISBN 8487527108.

BABIANO, J.; FERNÁNDEZ ASPERILLA, A. 2009. La patria en la maleta. Historia social de la emigración española a Europa. Madrid: Fundación 1ㅇ de mayo y Ediciones GPS. ISBN 9788497213936.

CASTIELLO, CH. 2010. Con maletas de cartón. La emigración española en el cine. Donostia/San Sebastián: Tercera Prensa s.I. ISBN 9788496993150.

MARTÍN PÉREZ, S. 2012. La representación social de la emigración española a Europa (1956-1975). El papel de la televisión y otros medios de comunicación. Madrid: Ministerio de Empleo y Seguridad Social. Subdirección General de Información Administrativa y Publicaciones. ISBN/ISSN NIPO 270-12-106-7.

2013. La historia de la humanidad es historia del nomadismo: Restrepo. En: Informador. [Consulta 8 de marzo de 2017]. Disponible en: http://www.informador.com.mx/cultura/2013/461935/6/la-historia-de-la-humanidad-es-historia-del-nomadismo-restrepo.htm

BATLLE, J. 2014. 'Hermosa juventud': Esto es lo que hay. En: La Vanguardia. [Consulta 11 de marzo de 2017]. Disponible en: http://www.lavanguardia.com/cine/20140530/54409462659/hermosa-juventud-critica-de-cine.html

BOYERO, C. 2014. Crónica de la intemperie. En: El País. [Consulta 11 de marzo de 2017]. Disponible en: http://cultura.elpais.com/cultura/2014/05/29/actualidad/1401374129_292497.html

RODRÍGUEZ, O. 2015. Crítica de "Perdiendo el norte» (***): Vente a Alemania, don José. En: $A B C$. [Última consulta: 11 de marzo de 2017]. Disponible en:

http://hoycinema.abc.es/critica/20150306/abci-perdiendo-norte-pelicula-opiniones-201503051159.html

\footnotetext{
${ }^{17}$ Serie de televisión. España, 2016. Director: Nacho G. Velilla, Oriol Capel, Antonio Sánchez, David S. Olivas, Antonio Sánchez, Oriol Ferrer y Javi Luna. Guión: Oriol Capel, David S. Olivas, Antonio Sánchez, Marina Pérez, Jorge Anes y Natalia Durán. Fotografía: Teo Delgado. Música: Juanjo Javierre. Intérpretes: Antonio Velázquez, Belén Cuesta, Kimberley Tell, Manuel Burque.
} 